\title{
Os sentidos do ensino de Língua Portuguesa na BNCC para o Ensino Médio
}

\author{
The Senses of Portuguese Language Teaching at BNCC for High School \\ Izaildes Cândida Oliveira Guedes ${ }^{1}$ \\ Universidade do Estado de Mato Grosso \\ Joelma Aparecida Bressanin ${ }^{2}$ \\ Universidade do Estado de Mato Grosso
}

Neures de Paula Soares ${ }^{3}$

Universidade do Estado de Mato Grosso

\begin{abstract}
- RESUMO: Neste texto realizamos um estudo sobre o modo como está posto o ensino da Língua Portuguesa na Base Nacional Comum Curricular (BNCC) para o Ensino Médio. Traçamos um percurso de leitura e análise sobre o ensino de Língua Portuguesa, nas escolas brasileiras, iniciando pelo modo como esta língua foi institucionalizada no Brasil desde o contato dos portugueses com os povos indígenas até a criação de políticas públicas como é o caso da BNCC. Este trabalho ancora-se no campo disciplinar da História das Ideias Linguísticas articulado à Análise de Discurso de escola francesa. As leituras levaram-nos a compreensão de que o ensino de língua é colocado de modo subsumindo no excesso de habilidades propostas para cada campo de atuação social da Base, além de demonstrar como as políticas linguísticas se consolidam enquanto condições materiais, regulando as instâncias de poder, bem como o modo de constituição dos sujeitos.
\end{abstract}

- PALAVRAS-CHAVE: Políticas Linguística; Escola; BNCC.

- ABSTRACT: In this text, we carried out a study about the way in which the teaching of the Portuguese Language is placed in the National Curricular Common Base (BNCC) for High School. In this paper, we will examine the relationship between the Portuguese language and the Portuguese language in the context of the Portuguese language. as the case of the BNCC. We reflect on how this document, which is configured as a language policy, presents the proposal for the teaching of Portuguese Language. Such reflections are anchored in the disciplinary field of the History of Linguistic Ideas, articulated to the Discourse Analysis of french school and the Historical Semantics of Enunciation. The readings have led us to an understanding that language teaching is subsumed in the excess of skills proposed for each field of social action of the Base. In the same sense, the analysis demonstrates how linguistic policies are consolidated the material conditions, regulating the instances of power, as well as the mode of constitution of the subjects.

- KEYWORDS: Linguistic Politic; School; BNCC

\section{Introdução}

As reflexões que articulamos neste artigo, como sugere o título, versam sobre o modo como está proposto o ensino de Língua Portuguesa na versão da Base Nacional

\footnotetext{
${ }^{1}$ Doutoranda do Programa de Pós-graduação em Linguística da Universidade do Estado de Mato Grosso/UNEMAT. Cáceres-MT, Brasil. E-mail: izaguedes07@hotmail.com

2 Doutora em Linguística. Professora do Programa de pós-graduação em Linguística PPGL/UNEMAT. E-mail Joelmaab@hotmail.com

${ }^{3}$ Doutoranda do Programa de Pós-graduação em Linguística da Universidade do Estado de Mato Grosso/UNEMAT. Cáceres-MT, Brasil. E-mail: Neures_paula@hotmail.com
} 
Comum Curricular, de agora em diante BNCC, para o Ensino Médio, ainda em processo de discussão/aprovação. Tais reflexões ancoram-se nos campo disciplinar da História das Ideias Linguísticas, articuladas à Análise de Discurso de linha pechêutiana.

A História das Ideias Linguísticas, segundo Diniz (2012), é um campo interdisciplinar, ainda recente, que no Brasil, desenvolveu-se a partir da década de 90 do século XX e permite pensar a história do conhecimento sobre a língua e sua relação com o Estado, possuindo estreita relação teórica com a Análise de Discurso pêchetiana e a Semântica Histórica Acontecimento.

Pensar o ensino da língua portuguesa é estabelecer uma relação com as políticas linguísticas, uma vez que estas constituem "as condições materiais de base que vão garantir a tomada de posição das instâncias de poder, visando regular as práticas linguageiras”. (MARIANI, 2003, p. 78).

Nessa medida, uma política estabelece regras para a efetiva utilização de uma língua ou para o silenciamento de outra, organiza simultaneamente os espaços institucionais por onde as línguas circulam e o modo como elas circulam. Segundo Mariani (Op. cit), uma política linguística regulamenta a língua com que os sujeitos vão fazer a história significar e, ao mesmo tempo, serão significados por essa mesma história.

Com a criação da proposta de uma Base Nacional Comum Curricular para o Ensino Médio, passamos a pensar como essa proposta, que se configura enquanto política linguística, apresenta o ensino de língua. Assim, neste artigo, nosso olhar alude sobre a proposta da BNCC para a área de Linguagens, especificamente, sobre a disciplina de Língua Portuguesa no Ensino Médio, objetivando analisar como essa política linguística apresenta a proposta de ensino para esse componente curricular.

E por esta razão torna-se importante explicitar como o ensino da Língua Portuguesa tem-se configurado historicamente, no Brasil, bem como discorrer sobre as condições de produção da BNCC e sua relação com as políticas de língua.

\section{Base Nacional Comum Curricular: condições de produção}

A BNCC "é um documento de caráter normativo que define o conjunto orgânico e progressivo de aprendizagens essenciais que todos os alunos devem desenvolver ao longo das etapas e modalidades da Educação Básica, de modo que tenham assegurados seus direitos de aprendizagem e desenvolvimento" (BNCC 2017, p. 7). É prevista pela Constituição de 1988, Lei de Diretrizes e Bases da Educação Nacional de 1996, Diretrizes Curriculares Nacionais Gerais da Educação Básica e pelo Plano Nacional de Educação - Lei 13.005/2014.

A primeira versão do documento foi colocada para consulta pública em 2015; em 2016 foi apresentada pelo CONSED $^{4}$ e UNDIME $^{5}$ que levaram a segunda versão para todo o país; e em 2017 o Ministério da Educação (MEC) entregou ao Conselho Nacional de Educação (CNE) a terceira versão da BNCC, com as partes da Educação Infantil e do Ensino Fundamental, ano também da homologação desses textos. Quanto à BNCC do Ensino Médio, corpus deste trabalho, o texto passou por apreciação em audiências públicas que aconteceram em 2018.

Conforme consta no site ${ }^{6}$ próprio da BNCC, o texto foi construído a partir de consultas públicas, de consultorias universitárias, de comitês de especialistas, de

\footnotetext{
4 - Conselho Nacional de Secretários de Educação (CONSED)

5 - União Nacional dos Dirigentes Nacional de Educação (UNDIME)

${ }^{6} \mathrm{http}: / /$ basenacionalcomum.mec.gov.br/ . Acesso em 25 de julho de 2018.
} 
técnicos, da participação de gestores das redes de ensino, diretores escolares, professores, coordenadores, pais, alunos e especialistas.

Como política educacional, a BNCC deverá constituir-se como uma referência nacional comum e obrigatória para a elaboração dos currículos e propostas pedagógicas das redes e instituições de ensino. No texto de introdução, a BNCC é apresentada como um documento norteador que modificará as ações educacionais. Assim, trata-se de uma

Referência nacional para a formulação dos currículos dos sistemas e das redes escolares dos Estados, do Distrito Federal e dos Municípios e das propostas pedagógicas das instituições escolares, a BNCC integra a política nacional da Educação Básica e vai contribuir para o alinhamento de outras políticas e ações, em âmbito federal, estadual e municipal, referentes à formação de professores, à avaliação, à elaboração de conteúdos educacionais e aos critérios para a oferta de infraestrutura adequada para o pleno desenvolvimento da educação. (BNCC, 2017).

No mote dessa política, o ensino de Língua Portuguesa é concebido dentro de um conjunto de campos ${ }^{7}$ como: campo da vida pessoal; campo das práticas de estudo e pesquisa; campo jornalístico-midiático; campo de atuação na vida pública; campo artístico. Em cada campo é apresentado habilidades que se relacionam às sete competências específicas da área da linguagem. Por conseguinte, há ainda, Parâmetros para a organização/progressão curricular que delimitam alguns conteúdos.

Nessa esteira, o ensino de língua é, a nosso ver, colocado de modo subsumindo no excesso de habilidades propostas para cada campo de atuação social.

\section{Um percurso histórico sobre o ensino da Língua Portuguesa}

O ensino de língua no Brasil desde os primeiros contatos dos portugueses com os povos indígenas perpassa por dentre outras questões, algumas que são de cunho estritamente político como, por exemplo, a construção de um saber da língua indígena como meio para a domesticação, via catequização, e com ela o apagamento cultural e a escravização dos povos nativos, embora, esse seja um efeito do político, cujas formações discursivas procuravam mascarar esse efeito de perversidade, da imposição, fazendo-o ser compreendido sob a aparência das "boas intenções".

Segundo Dias (2001), a Coroa portuguesa, motivada por um movimento de consolidação das línguas nacionais que já estava ocorrendo em vários países europeus no século XVIII, começou a fazer uma imposição incisiva da língua nacional na colônia, determinando "na carta régia de 12 de setembro de 1727 [...], ao Superior dos religiosos da Companhia de Jesus no Maranhão, que a língua portuguesa fosse ensinada aos índios para o benefício da Coroa e dos moradores da terra.” (p. 186). Com essa medida, Portugal institucionalizou, portanto, o ensino da língua portuguesa no Brasil.

Sabe-se que daí em diante, em curto espaço de trintas anos, a Coroa portuguesa implementou uma política de ensino da Língua Portuguesa no Brasil, primeiramente, sob o escopo de um discurso convincente que dava lugar à efeitos de sentido de "benefício" para os povos nativos, e depois, com medidas coercitivas, como o decreto do Marquês de Pombal, de 1757, que impôs o silenciamento, tanto da língua geral ${ }^{8}$, quanto das demais línguas faladas na costa brasileira.

\footnotetext{
${ }^{7}$ Os campos de atuação remetem ao modelo de redesenho curricular do programa de Ensino Médio Inovador/ProEMI que foi implementado nas instituições escolares visando à escola integral.

${ }^{8}$ Era a língua oficial em uso no Brasil, naquele momento, se dava pela mistura do Português com o Tupi.
} 
Para Dias (2001) tem-se aí um problema de língua, posto que, a Língua Portuguesa, que passou a ser ensinada no Brasil, que a nosso ver, era tomada em uma perspectiva extremamente purista e estruturalista, não era a mesma que continuou a ser usada, tendo em vista que se tratava de falantes com uma constituição histórico-cultural completamente diferente das pessoas que frequentavam a escola em Portugal, ou seja, o ensino da Língua Portuguesa no Brasil já se oficializou com uma cisão, pois falava-se uma língua e estudava/escrevia outra. Nas palavras do autor (idem),

A questão da língua no Brasil tem suas raízes na profunda separação entre língua escrita e língua falada, haja vista que não tinha havido interesse, por parte da metrópole, de implantar uma política cultural e educacional abrangente na colônia. Na implantação do ensino de língua no Brasil, buscou-se cultivar os padrões de língua escrita vigentes em Portugal, falada por uma elite situada nos principais centros urbanos e a língua portuguesa, de base oral, utilizada pela população rural, analfabeta, e pela maioria da população das cidades que não tinha acesso à escola. (DIAS, 2001, p. 187).

Em uma sequência histórico-cronológica temos, conforme Orlandi (2002), o século XIX como um dos mais significativos na história de constituição da nação, no qual o País conquistou sua independência e com isso tornou-se autônomo para organizar as políticas de estado, dentre elas, o ensino da língua nacional. Período esse que suscitou debates relevantes e pertinentes acerca da constituição e do ensino da língua nacional enquanto uma variante do português ou como uma nova língua que, embora descendente desta, tinha já outras particularidades que eram próprias de sua constituição.

Com a independência, o ensino de língua, no Brasil, deixou de ser, segundo Orlandi (2002), uma questão a ser tratada com os portugueses, passando à responsabilidade dos brasileiros, os quais incumbiram-se de produzir os instrumentos linguísticos, o que reverbera para, dentre outras questões, a estabilização da escrita por meio dos acordos ortográficos. Isso, segundo a autora, produz uma mudança na "relação do brasileiro com a sua língua" (p. 203) e amplia, a partir dessa institucionalização da língua nacional, a produção e a circulação do conhecimento, bem como, a produção intelectual.

O Século XX foi considerado de grandes avanços no campo dos estudos da língua tanto na Europa quanto no Brasil, inclusive com o reconhecimento da linguística como ciência. Para o Brasil, a introdução da linguística no campo das ciências, foi sem dúvida, um fator relevante, pois ainda estavam em alta os debates em torno da língua nacional, os quais perpassavam por questões como identidade, nomeação, produção de gramáticas, produção da Nomenclatura Gramatical Brasileira (NGB), dentre outras, que recaiam sobre o ensino da língua.

Segundo Orlandi (Idem), a passagem da linguística de disciplina à ciência, instaurou um corte no modo como língua e sociedade se significaram mutuamente até aquele momento, pois:

Se no século XIX, as Humanidades é que estabelecem um quadro para os estudos da linguagem, como gramática, na definição da especificidade de um país com sua sociedade e suas instituições, no século XX, sobretudo em seus albores, o Estado brasileiro já constituído, demanda uma relação definida com a ciência, e os estudos ganham seu lugar particular no quadro científico e na formação de 
quadros especializados para seu ensino. [...] No século XIX, as Humanidades 'formatam' o conhecimento da linguagem; a partir dos anos 70 do século XX, é o estudo da linguagem que 'formata' as humanidades. (ORLANDI, 2002, p. 207).

Desse modo, a partir dos anos finais do século XX e nas duas primeiras décadas do século XXI o Brasil tem buscado consolidar uma política de ensino da Língua Portuguesa que corresponda ao movimento apresentado por Orlandi (op. cit), o que tem sido feito por meio do Ministério da Educação, com a criação de diversas políticas como os Parâmetros Curriculares Nacionais (PCNs), as Orientações Curriculares Nacionais (OCNs) e a BNCC. Nas políticas ora referidas, o componente curricular Língua Portuguesa tem dedicado cada vez menos espaço ao ensino da língua em uma perspectiva gramatical para dar lugar ao estudo do texto, especificamente, na perspectiva do gênero textual, visando uma formação crítico-social e para o trabalho. Segundo Silva,

Os PCN, em seu volume 2, afirmam, desde a sua "apresentação", que a escola ao ensinar a Língua Portuguesa tem a responsabilidade de garantir a todos os seus alunos o acesso aos saberes lingüisticos, necessários para o exercício da cidadania, direito inalienável de todos. Este lugar estratégico atribuído à escola para a constituição de uma determinada cidadania está, pois, centrado nos saberes linguísticos necessários, que a instituição pode transmitir, para provocar as mudanças e rupturas desejáveis pelo Estado brasileiro. (SILVA, 2001, s/p).

Quanto às orientações para o ensino de Língua Portuguesa, no Ensino Médio, a $\mathrm{BNCC}$, fortemente ancorada na perspectiva de gêneros textuais, aponta igualmente para uma proposta muito próxima à dos $\mathrm{PCNs}$, conforme se lê:

Ao chegar ao Ensino Médio, os estudantes já têm condições de participar de forma significativa de diversas práticas sociais que envolvem a linguagem, pois, além de dominarem certos gêneros textuais/discursivos que circulam nos diferentes campos de atuação social considerados no Ensino Fundamental, eles desenvolveram várias habilidades relativas aos usos das linguagens. Cabe ao Ensino Médio aprofundar a análise sobre as linguagens e seus funcionamentos, intensificando a perspectiva analítica e crítica da leitura, escuta e produção de textos verbais e multissemióticos, e alargar as referências estéticas, éticas e políticas que cercam a produção e recepção de discursos, ampliando as possibilidades de fruição, de construção e produção de conhecimentos, de compreensão crítica e intervenção na realidade e de participação social dos jovens, nos âmbitos da cidadania, do trabalho e dos estudos. (grifos nosso) (BNCC, 2017, p. 490)

A concepção de ensino de língua posta nas políticas educacionais das últimas três décadas, se apresenta, do ponto de vista discursivo (PÊCHEUX, 2002), como um efeito de sentido de uniformização dos sujeitos que se faz pelo jurídico, ou seja, a proposta tem que ser capaz de dar "aos jovens", o que em um processo parafrástico (ORLANDI, 2015), pode ser compreendido como "todos os jovens brasileiros", as mesmas condições de aprendizagem, produzindo um efeito de apagamento das 
desigualdades que são de ordem histórico-cultural e afeta o modo como cada sujeito se inscreve e significa no processo de escolarização.

Parafraseando Di Renzo (2002, p. 101), diríamos que a questão do ensino da língua afeta mutuamente sujeito e Estado, visando, cada vez mais, a produção de políticas capazes de construir/atingir um modelo determinado de sociedade.

\section{Políticas Linguísticas}

Compreendendo a BNCC como uma política linguística, que impõe a forma de como o ensino de língua deve acontecer, é que julgamos necessário refletirmos sobre essa ação que, subsidiada pelo Estado, administra sentidos outros para o conhecimento da/sobre língua. É no modo como se dão tais políticas e sua implementação que o Estado homogeneíza sentidos e produz um modo de individuação do sujeito adequandoo às exigências sociais.

Pensar tais políticas linguísticas é, também, pensar a língua com aquilo que lhe é próprio, o político. Assim, podemos adotar o termo "política de língua", conforme propõe Orlandi (2007) ao dizer que:

[...] não há possibilidade de se ter língua que não esteja já afetada desde sempre pelo político. Uma língua é um corpo simbólico-político que faz parte das relações entre sujeitos na sua vida social e histórica. Assim, quando pensamos em política de línguas já pensamos de imediato nas formas sociais sendo significadas por e para sujeitos históricos e simbólicos, em suas formas de existência, de experiência, no espaço político de seus sentidos (p.8).

De fato, a julgar pelas leituras de outras políticas linguísticas estabelecidas, como por exemplo, os PCNs, ENEM e as OCs de Mato Grosso, observa-se que há uma proposta de formação do sujeito para que este desempenhe as práticas sociais capitalistas, ou seja, sejam preparados tão somente para o mercado de trabalho.

Ao pensar a presença do político na linguagem, em uma noção mais restrita e técnica, Orlandi (2002) toma política de língua ou política linguística, não como, necessariamente, sinônimas. Para a autora, haverá sempre diferentes sentidos a atribuir ao que é política linguística. Os sentidos vão desde a "tematização formal de uma política linguística explicitada, planejada, organizacional, até a observação de processos institucionais menos evidentes, presentes de forma implícita nos usos diferenciados (e que produzem diferenças) das línguas". (ORLANDI, 2002, p. 95).

Nessa diversidade de sentidos, Orlandi (idem) apresenta três posições sobre política linguística, que são: 1) As políticas linguísticas como razões de Estado, das Instituições que apresentam a questão da unidade como valor (como princípio ético); 2) As políticas linguísticas como razões que regem as relações entre povos, entre nações, Estados: a questão da dominação como valor (como princípio ético); 3) As políticas linguísticas como razões relativas aos que falam as línguas: a questão da diversidade como valor (como princípio ético).

Ainda, segundo a autora, no tocante às políticas linguísticas, é importante que haja um espaço em que o sujeito, posto em contato com a língua, possa elaborar sua situação de contato e dinamizar sua participação no trabalho de compreensão e de formulação de sua situação linguística. Desse modo, torna-se possível atingir o sentido mais importante de uma política linguística que é "praticá-la não como uma vontade 
exclusiva do poder, mas como um trabalho que coloca em relação o político, o sujeito, a língua, as línguas e o saber sobre as línguas". (ORLANDI, 2002, p. 98).

Ao pensarmos sobre como a BNCC apresenta o ensino da Língua Portuguesa faz-se necessário observarmos como tal política compreende a língua e qual relação é estabelecida entre língua e sujeito. Di Renzo (2012), ao analisar os regulamentos de ensino do Liceu cuiabano historiciza uma política linguística que materializa uma relação da língua com o sujeito puramente comunicacional "como se os sujeitos devessem se apropriar da língua apenas o suficiente para serem objetivos quando quisessem se exprimir", pressupondo que o domínio de certas estruturas da língua fosse necessário somente para determinadas situações, como se o sujeito se constituísse apenas por elas.

Observa-se, desde então, que essa concepção de língua tem perpassado diversas políticas linguísticas, reverberando para as concepções de língua concebidas nos manuais de ensino e programas predominantes nas instituições escolares ${ }^{9}$. Contudo, é preciso considerar que ao tomar a língua na concepção de instrumento de comunicação, tem-se uma língua que não se inscreve na história, constituindo o sujeito, pois "a língua é constituida por, a língua funciona, a língua produz (não é "veículo"), a língua se materializa no texto, a língua, sujeita a falhas, se inscreve na história para significar". (ORLANDI, 2014, p. 88).

A BNCC enquanto instrumento oficial de uma política governamental direciona as práticas tanto linguísticas como pedagógicas na Escola. E enquanto instrumento linguístico ${ }^{10}$ faz funcionar um papel legislador do Estado. Nessa medida, analisar essas textualidades como instrumentos linguísticos é pensar em uma formação do imaginário de sociedade que se constitui por sujeitos que se identificam como sujeitos escolarizados, que atendem a certo domínio da língua e se significam através da relação com a língua e a história.

Ao conceber a BNCC como um instrumento linguístico, estamos considerandoa na relação do sujeito com os sentidos e a história. De acordo com Orlandi (2001, p. 9), "tanto a gramática quanto o dicionário, ou o ensino e seus programas, [...] são uma necessidade que pode e deve ser trabalhada de modo a promover a relação do sujeito com os sentidos, relação que faz a história e configura as formas da sociedade".

Assim, é possível dizer que as políticas linguísticas produzem sentidos e efeitos tanto para os sujeitos quanto para a sociedade, e é justamente nesse ponto que refletimos sobre o modo como a BNCC apresenta o ensino da Língua Portuguesa e os efeitos de sentido que se produz.

\section{BNCC: O ensino de Língua Portuguesa}

A língua Portuguesa enquanto disciplina é um componente que deve ser oferecido nos três anos do Ensino Médio conforme a Lei n ${ }^{0} 13.415 / 2017$. No decorrer do texto são apresentadas habilidades, por campo de atuação social, sem indicação de seriação. Tais habilidades são tomadas em uma dimensão mais aprofundada, pois são compreendidas, pela política, que a aquisição destas se deu no Ensino Fundamental, por meio do ensino dos gêneros textuais/discursivos.

\footnotetext{
${ }^{9}$ Para uma leitura mais aprofundada, Oliveira (2015) "Os "discursos sobre” texto nas Políticas Linguísticas para o Ensino Médio, e Di Renzo (2012) "O Estado, a Língua nacional e a construção das políticas linguísticas”.

${ }^{10}$ Instrumentos linguísticos são aqui compreendidos como produção de um saber metalinguístico e não apenas um artefato. Ao considerar o uso desses instrumentos na escola, na perspectiva da HIL, significa considerar a construção da produção de objetos históricos com consequências sobre as políticas das línguas. (ORLANDI, 2001).
} 
Ao chegar ao Ensino Médio, os estudantes já têm condições de participar de forma significativa de diversas práticas sociais que envolvem a linguagem, pois, além de dominarem certos gêneros textuais/ discursivos que circulam nos diferentes campos de atuação social considerados no Ensino Fundamental, eles desenvolveram várias habilidades relativas aos usos das linguagens (BNCC, 2017, p. 490).

Assim, quanto à área de linguagens, no Ensino Médio tem-se "a responsabilidade para a consolidação e ampliação das habilidades de uso e de reflexão sobre as linguagens - artísticas, corporais e verbais (oral ou visual-motora, como LIBRAS e escrita)". (BNCC, 2017, p. 474).

Observa-se também que o ensino da língua dar-se-á pela integração das diversas linguagens que são definidas nos campos de atuação social, um dos principais eixos organizadores da proposta, objetivando a cidadania e o trabalho.

Para orientar uma abordagem integrada dessas linguagens e de suas práticas, a área define que os campos de atuação social são um dos seus principais eixos organizadores. Segundo essa opção, a área propõe que os estudantes possam vivenciar experiências significativas com práticas de linguagem em diferentes mídias (impressa, digital, analógica), situadas em campos de atuação social diversos, vinculados com o enriquecimento cultural próprio, as práticas cidadãs, o trabalho e a continuação dos estudos. (BNCC, 2017, p. 477).

Tem-se, então, a manutenção de um ensino voltado para formar um cidadão crítico e preparado para o trabalho, ou seja, tem-se ainda a "cidadania" como efeito de sentido, efeito ideológico tal como materializado nos Parâmetros Curriculares Nacionais. (SILVA, 2017, p.318).

A professora e pesquisadora, Mariza Vieira da Silva, ao analisar a BNCC/2016 questiona a proposta que coloca o trabalho como uma demanda do ensino. Para a autora, é preciso perguntar "que trabalho é este dada às condições atuais de precarização, instabilidade e volatilidade do mesmo nos espaços urbanos redesenhados, resignificados de forma espantosa em termos de consumo, de modos de vida, de fluxos de produção e dos capitais". (SILVA, 2017, p. 323).

O texto da BNCC/2017 registra que o trabalho é um elemento que perpassa todos os campos de atuação social e apresenta dois modos para defini-lo. Um proposto pelo parecer do Conselho Nacional de Educação/CEB n ${ }^{\circ}$ 5/201164 que diz:

o trabalho é princípio educativo à medida que proporciona compreensão do processo histórico de produção científica e tecnológica, como conhecimentos desenvolvidos e apropriados socialmente para a transformação das condições naturais da vida e a ampliação das capacidades, das potencialidades e sentido humanos. (BNCC, 2017, p. 497)

Assim, compreendendo o trabalho por esse princípio educativo, é que segundo o arquivo analisado, "procura-se oferecer ferramentas de transformação social por meio da apropriação dos letramentos da letra e dos novos multiletramentos, os quais supõem maior protagonismo por parte dos estudantes, orientados pela dimensão ética, estética e política". (BNCC/2017, p. 497). Já o segundo modo, pensa o trabalho enquanto 
[...] atividade responsável pela (re) produção da vida material também é considerado pelo repertório de práticas, letramentos e culturas que se pretende que sejam contempladas, pela possibilidade de exercício da criatividade, pelo desenvolvimento de habilidades vinculadas à pesquisa, a resoluções de problemas, ao recorte de questões problema, ao planejamento, ao desenvolvimento e à avaliação de projetos de intervenção, pela vivência de processos colaborativos e coletivos de trabalho, entre outras habilidades [...]. (BNCC, 2017, p. 498).

Ao observar essa definição de trabalho notamos um deslizamento de trabalho enquanto atividade do mercado, inscrita em uma formação capitalista para a definição de trabalho como competência que visa desenvolver habilidades para tornar-se um sujeito autônomo. Nesse sentido, destacamos a razão das competências e das diversas habilidades nos campos de atuação, "naturalizando de forma mais radical o sentido de currículo como controle”. (SILVA, 2017, p. 325).

Assim como proposto nos PCNs, o gênero textual aparece como centralidade na BNCC. Ao dizer o que cada campo de atuação social preconiza, apresentam-se os gêneros textuais/discursivos para contextualizar as práticas de linguagem. Assim, podese observar em cada campo:

O campo da vida pessoal está em questão também possibilitar vivências significativas de práticas colaborativas em situações de interação presenciais ou em ambientes digitais e aprender [...]

No cerne do campo de atuação na vida pública está o domínio básico de textos legais e a discussão e o debate de ideias, propostas e projetos [...] A discussão sobre o Estatuto da Juventude e seu cumprimento e a análise e produção coletiva de projetos de lei também são postos em evidência. Análises de campanhas e programas políticos e de políticas públicas, bem como de estratégias de acompanhamento do exercício do mandato de governantes, também são consideradas em algumas das habilidades propostas.

Em relação ao campo jornalístico-midiático Além dos gêneros propostos para o Ensino Fundamental, são privilegiados gêneros mais complexos relacionados com a apuração e o relato de fatos e situações (reportagem multimidiática, documentário etc.) e com a opinião (crítica da mídia ensaio, vlog de opinião etc.). Textos, vídeos e podcasts diversos de apreciação de produções culturais também são propostos, a exemplo do que acontece no Ensino Fundamental, mas com análises mais consistentes, tendo em vista a intensificação da análise crítica do funcionamento das diferentes semioses.

No campo artístico-literário: Gêneros e formas diversas de produções vinculadas à apreciação de obras artísticas e produções culturais (resenhas, vlogs e podcasts literários, culturais etc.) ou a formas de apropriação do texto literário, de produções cinematográficas e teatrais e de outras manifestações artísticas (remidiações, paródias, estilizações, videominutos, fanfics etc.) continuam a ser considerados associados a habilidades técnicas e estéticas mais refinadas. 
O campo das práticas de estudo e pesquisa mantém destaque para os gêneros e habilidades envolvidos na leitura/escuta e produção de textos de diferentes áreas do conhecimento e para as habilidades e procedimentos envolvidos no estudo. (BNCC, 2017, p. 479-480)

Ao pretender que o ensino abranja uma gama de gêneros correspondentes a aspectos como do individual/social, artístico/literário, pesquisa/acadêmico, tecnológico/midiático, objetivando o uso pragmático da língua, por meio das diversas linguagens, toma-se o ensino de língua em uma fragmentação e dispersão ${ }^{11}$, acompanhadas de hierarquização e superposição para construir uma base comum de trabalho na Escola, como afirma Silva (2017).

Esse modo de conceber o ensino da Língua Portuguesa nos coloca questões sobre o arcabouço conteudístico para o trabalho do professor, assim como para a recepção por parte dos alunos. É possível se trabalhar todos os gêneros que estão em circulação? O aluno precisa aprender, na escola, todos os gêneros dos quais utilizará nas práticas sociais? O que se observa é uma quantidade exacerbada de textos que vão desde os mais simples aos considerados mais complexos. E, ainda, nota-se um apagamento dos textos acadêmicos em que, somente, se vê na escola, como por exemplo, os resumos, as sínteses e as resenhas.

Outra questão que se coloca, no arquivo analisado, é a integração de temas advindos de outras áreas do conhecimento. Em todos os campos de atuação social, é possível encontrar proposto o estudo de temas como os Direitos Humanos, políticas públicas, o fenômeno da pós-verdade, a criação e participação em projetos de intervenção social, projetos editoriais independentes, a mídia como elemento independente para a democracia; ainda discussões sobre os discursos de ódio, o Estatuto da Juventude e seu cumprimento e a análise e produção coletiva de projetos de lei; análises de campanhas e programas políticos e de políticas públicas.

Ao nosso modo de interpretar, o sentido que se produz é o de "liquidez" do ensino da língua, como já mencionamos neste texto, pois, toma-se a disciplina de Língua Portuguesa, lugar possível de ensino da língua, como "carro chefe" para se trabalhar outras disciplinas como a filosofia, a sociologia e a história. Isso remete à política pública, tão polemizada, da reforma do Ensino Médio, aprovada em 2017, que retira das matrizes curriculares tais disciplinas.

Desse modo, retomamos o que apresentamos, neste texto, sobre os estudos de Dias em que o ensino da Língua Portuguesa no Brasil já se oficializava com uma cisão, pois se falava uma língua e estudava/escrevia-se outra, a qual relacionava à língua da elite situada nos principais centros urbanos. Nessa medida, podemos pensar sobre, que tipo de relação se estabelece para o ensino de língua quando se propõe trabalhar com uma vasta quantidade de gêneros e uma demanda exaustiva de temas? Que língua está sendo ensinada? Será a língua daqueles que podem acessar todos os gêneros textuais/discursivos? Ou daqueles que desconhece a existência de um blog, chat ou vlogs e podcasts culturais, gameplay etc. Haverá aí, efetivamente, o ensino da língua?

Em se tratando do ensino da língua há o sentido de um trabalho com o texto e os gêneros textuais, conforme já analisamos. Contudo, é importante destacar que o trabalho com a língua, nas políticas linguísticas, dá-se predominantemente, pelas teorias linguísticas como a pragmática e o funcionalismo (SILVA, 2017, p. 325) desde a

\footnotetext{
11 “A fragmentação (não divisão) e a dispersão, consideradas as hierarquizações e superposições, presentes na BNCC/2017, acabam por construir uma unidade imaginária, tomando como equivalentes diferentes demandas da sociedade, trabalhando dessa maneira a contradição entre o específico e o universal, o individual e o social, e produzindo e efeito de consenso: um outro modo de domesticar o político". (SILVA, 2017, p. 322).
} 
implementação dos PCNs/98. Podemos dizer, considerando a leitura e a análise dos arquivos, que há um movimento com as teorias linguísticas que perpassa esta política. Mesmo não demonstrando com clareza os conceitos de determinadas teorias, percebe-se a inserção da sociolinguística e da Análise de Discurso em suas diferentes concepções epistemológicas.

Desse modo, concordamos com Silva (2017) ao afirmar que esses movimentos nos discursos dos documentos oficiais oferecem condições para estudos e pesquisas a serem empreendidos, pois não é suficiente dizer que produzem consensos, mas, há de se apreender o modo como o fazem.

\section{Algumas Considerações}

A análise demonstra como as políticas linguísticas se consolidam enquanto condições materiais, regulando as instâncias de poder, bem como o modo de constituição dos sujeitos. Como bem afirma Orlandi (2002), as políticas linguísticas apresentam-se, mantendo o efeito de unidade, como uma língua que todos têm acesso; de dominação em que se aprende a língua que a escola ensina, sem levar em conta a diversidade constitutiva dessa língua.

A BNCC para o Ensino Médio apresenta-se como uma política de língua que toma como eixo para o ensino uma vasta quantidade de gêneros textuais/discursivos. Trata-se de um ensino adequado às práticas sociais que, ideologicamente, coloca a língua como acesso a cidadania e ao trabalho. Trabalho este que se apresenta em duas acepções, como atividade capitalista e como competência em que deriva para diversas habilidades necessárias ao uso da língua. Mantendo, com isso, o predomínio das teorias linguísticas como a pragmática e o funcionalismo.

\section{REFERÊNCIAS}

BRASIL. Base Nacional Comum Curricular. $3^{\text {a }}$ versão revista. Brasília, MEC, 2017. Disponível em: http://basenacionalcomum.mec.gov.br/ acesso em: 25 de junho de 2018. DI RENZO, Ana Maria. Liceu Cuiabano: Língua Nacional, Religião e Estado. In: Institucionalização dos estudos da linguagem: a disciplinarização das ideias linguísticas/ Eni P. Orlandi, Eduardo Guimarães (Orgs.) Campinas, SP: Pontes, 2002

Estado, a Língua Nacional e a Construção das Políticas Linguísticas.

Campinas, SP. Pontes Editores, 2012.

DIAS, Luiz Francisco. O nome da língua do Brasil: uma questão polêmica. In: História das idéias lingüísticas: construção do saber metalinguístico e constituição da língua nacional. Campinas, SP: Pontes; Cáceres, MT: Unemat Editora, 2001.

Mariane Bethania. Políticas de Colonização Linguística. In: Espaços de circulação da linguagem. Revista do Programa de Pós-graduação em Letras da Universidade Federal de Santa Maria. ed. 27, dez. 2003.

ORLANDI, Eni P. Apresentação. In: ORLANDI, Eni P. (org). História das ideias linguísticas. Cáceres: Unemat Editora, 2001.

Língua e conhecimento linguístico. Para uma história das Ideias no Brasil.

São Paulo: Cortez, 2002.

Ciência da Linguagem e Políticas: anotações ao pé da letra. Campinas, SP:

Pontes Editores, 2014.

Análise de Discurso: princípios e procedimentos. 12 ed. Campinas, SP: Pontes

Editores, 2015. 
SILVA, Mariza Vieira. O Português do Brasil: a constituição de uma língua nacional. Palestra proferida na III semana Universitária da Universidade Católica de Brasília. Brasília-DF, (02 de outubro de 2001) Uma base Nacional Curricular Comum para a leitura nas escolas brasileiras: a política e o político. In: FLORES, Giovanna G. Benedito/ GALLO, Solange Maria Leda, LAGAZZI, Suzy/ NECKEL, Nádia Régia Mafli/ PFEIFFER, Claudia Castelanos/ ZOOPI-FONTANA, Mónica (Orgs.) Análise de Discurso em Rede: Cultura e Mídia. Campinas, SP: Pontes Editores, 2017. Volume 3.

PÊCHEUX, Michel. O discurso: estrutura ou acontecimento. Trad. Eni Puccinelli Orlandi. - 3 ed - Campinas, SP: Pontes, 2002.

http://movimentopelabase.org.br/a-construcao-da-bncc/Disponível acesso em: 25 de junho de 2018.

Recebido em: janeiro de 2019. Aprovado em: abril de 2019.

\section{Como citar este trabalho:}

GUEDES, I. C. O; BRESSANIN, J. A; SOARES, N. de P. Os sentidos do ensino de Língua Portuguesa na BNCC para o Ensino Médio. Traços de linguagem. V.3, n.1, p. 35-46, 2019. 